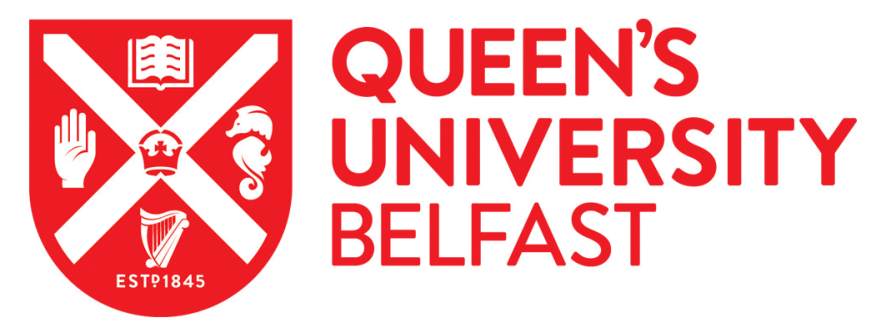

\title{
Determination of multi-mycotoxin occurrence in maize based porridges from selected regions of Tanzania by liquid chromatography tandem mass spectrometry (LC-MS/MS), a longitudinal study
}

Geary, P. A., Chen, G., Kimanya, M. E., Shirima, C. P., Oplatowska-Stachowiak, M., Elliott, C. T., Routledge, M. N., \& Gong, Y. (2016). Determination of multi-mycotoxin occurrence in maize based porridges from selected regions of Tanzania by liquid chromatography tandem mass spectrometry (LC-MS/MS), a longitudinal study. Food Control, 68, 337-343. https://doi.org/10.1016/j.foodcont.2016.04.018

\section{Published in:}

Food Control

Document Version:

Peer reviewed version

Queen's University Belfast - Research Portal:

Link to publication record in Queen's University Belfast Research Portal

\author{
Publisher rights \\ (C) 2016 Elsevier. \\ This manuscript version is made available under the CC-BY-NC-ND 4.0 license (http://creativecommons.org/licenses/by-nc-nd/4.0/), which \\ permits distribution and reproduction for non-commercial purposes, provided the author and source are cited.
}

\section{General rights}

Copyright for the publications made accessible via the Queen's University Belfast Research Portal is retained by the author(s) and / or other copyright owners and it is a condition of accessing these publications that users recognise and abide by the legal requirements associated with these rights.

Take down policy

The Research Portal is Queen's institutional repository that provides access to Queen's research output. Every effort has been made to ensure that content in the Research Portal does not infringe any person's rights, or applicable UK laws. If you discover content in the

Research Portal that you believe breaches copyright or violates any law, please contact openaccess@qub.ac.uk. 
Page 1 of 19

Determination of multi-mycotoxin occurrence in maize based porridges from selected regions of Tanzania by liquid chromatography tandem mass spectrometry (LC-MS/MS), a longitudinal study

Patrick A. Geary ${ }^{1}$, Gaoyun Chen ${ }^{1}$, Martin E. Kimanya², Candida P. Shirima³ ${ }^{3}$ Michalina OplatowskaStachowiak ${ }^{1}$, Christopher T. Elliott ${ }^{1}$, Michael N. Routledge ${ }^{4}$, Yun Yun Gong ${ }^{1 *}$

1. Institute for Global Food Security, Queen's University Belfast, United Kingdom

2. The Nelson Mandela Institution of Science and Technology, School of Life Sciences and Bioengineering, Arusha, Tanzania

3. Tanzania Food and Drugs Authority, Dar es Salaam, Tanzania

4. Division of Epidemiology, Leeds Institute of Genetics, Health and Therapeutics, University of Leeds, United Kingdom

\section{Abstract}

Residents of certain areas of Tanzania are exposed to mycotoxins through the consumption of contaminated maize based foods. In this study, 101 maize based porridge samples were collected from villages of Nyabula, Kikelelwa and Kigwa located in different agro-ecological zones of Tanzania. The samples were collected at three time points (time point 1, during maize harvest; time point 2, 6 months after harvest; time point 3,12 months after harvest) over a 1-year period. Ultra-performance liquid chromatography tandem mass spectrometry (UPLC-MS/MS) was used to detect and quantify 9 mycotoxins: aflatoxin $B_{1}\left(A F B_{1}\right)$, aflatoxin $B_{2}\left(A F B_{2}\right)$, aflatoxin $G_{1}\left(A F G_{1}\right)$, aflatoxin $G_{2}\left(A F G_{2}\right)$, fumonisin $\mathrm{B}_{1}\left(\mathrm{FB}_{1}\right)$, fumonisin $\mathrm{B}_{2}\left(\mathrm{FB}_{2}\right)$, deoxynivalenol $(\mathrm{DON})$, ochratoxin $\mathrm{A}(\mathrm{OTA})$ and zearaleneone $(\mathrm{ZEN})$ in the samples following a QuEChERS extraction method. Eighty two percent of samples were cocontaminated with more than one group of mycotoxins. Fumonisins $\left(\mathrm{FB}_{1}+\mathrm{FB}_{2}\right)$ had the highest percentage occurrence in all 101 samples (100\%) whereas OTA had the lowest $(5 \%)$. For all three villages the mean concentration of $\mathrm{FB}_{1}$ was lowest in samples taken from time point 2. Conversely, In Kigwa village there was a distinct trend that $\mathrm{AFB}_{1}$ mean concentration was highest in samples taken

Abbreviations: $A F B_{1}, A F B_{2}, A F G_{1}, A F G_{2}$, aflatoxin $B_{1}, B_{2}, G_{1}, G_{2}$; DON, deoxynivalenol; $F B_{1}, F_{2}$, fumonisin $B_{1}, B_{2}$; IARC, International Agency for Research on Cancer; LOD, LOQ, limit of detection, quantification; OTA, ochratoxin A; QuEChERS, Quick, Easy, Cheap, Effective, Rugged, Safe; UPLC-MS/MS, ultra-performance liquid chromatography tandem mass spectrometry; ZEN, zearalenone. 
from time point 2. DON concentration did not differ greatly between time points but the percentage occurrence varied between villages, most notably in Kigwa where $0 \%$ of samples tested positive. ZEN occurrence and mean concentration was highest in Kikelelwa. The results suggest that mycotoxin contamination in maize can vary based on season and agro-ecological zones. The high occurrence of multiple mycotoxins found in maize porridge, a common weaning food in Tanzania, presents a potential increase in the risk of exposure and significant health implications in children.

\section{Introduction}

Mycotoxins are naturally occurring toxic secondary metabolites produced by filamentous fungi which can contaminate many kinds of agricultural products. Toxigenic fungi are capable of growing under a wide range of atmospheric conditions depending on the species and they can contaminate crops during pre-harvest, immediate post-harvest, storage, transport and processing (Bennett \& Klich, 2003). Mycotoxins have been shown to contaminate a wide range of agricultural products including: cereals, nuts, fruit, spices and wine (Abia et al., 2013; Serra, Braga, \& Venâncio, 2005; Van de Perre et al., 2014; Yogendrarajah, Van Poucke, De Meulenaer, \& De Saeger, 2013). In the case of aflatoxins, they have also been detected in milk produced by cows that have consumed contaminated feed (Huang et al., 2013). Due to the ubiquitous presence of mycotoxins in both food and feed supply chains, and their association with various toxicological risks in both humans and animals, they have become a major economic and health concern.

More particularly, aflatoxin $B_{1}\left(A F B_{1}\right)$, aflatoxin $B_{2}\left(A F B_{2}\right)$, aflatoxin $G_{1}\left(A F G_{1}\right)$, aflatoxin $G_{2}\left(A F G_{2}\right)$, fumonisin $\mathrm{B}_{1}\left(\mathrm{FB}_{1}\right)$, fumonisin $\mathrm{B}_{2}\left(\mathrm{FB}_{2}\right)$, deoxynivalenol $(\mathrm{DON})$, ochratoxin $\mathrm{A}(\mathrm{OTA})$ and zearaleneone (ZEN) have all been recognised global health, agriculture and trade concerns due to the high occurrence and associated health impacts of these mycotoxins that has been found around the world. However, due to socio-economic and environmental factors, developing countries tend to be more severely affected by the threat of mycotoxins, especially aflatoxins, than developed countries (Wild \& Gong, 2010; Williams et al., 2004).

The growing recognition of the threat of mycotoxins has stimulated scientific research to better understand how exposure and toxicity impact human health. The toxicity varies among different types of mycotoxins but many have shown the capacity to be acutely toxic, carcinogenic, mutagenic and immunosuppressive (Bakırdere et al., 2012). The most fatal human aflatoxicosis outbreak occurred in 
Kenya, 2004, with 317 recorded cases of acute hepatitis and 125 deaths (Nyikal et al., 2004). Public health officials discovered that this was linked to the consumption of $\mathrm{AFB}_{1}$-contaminated maize and a case control study found that maize in case households had higher concentrations of aflatoxins compared to that of the maize from control households (Azziz-Baumgartner et al., 2005). The International Agency for Research on Cancer (IARC) classifies naturally occurring mixtures of aflatoxins $\left(\mathrm{AFB}_{1}+\mathrm{AFB}_{2}+\mathrm{AFG}_{1}+\mathrm{AFG}\right)_{2}$ ) as Group 1 carcinogens (International Agency for Research on Cancer, 2002). Previous studies have also provided evidence that aflatoxins may cause immune suppression as a result of decreased protein synthesis, changes in enzymatic activity and changes in metabolism or cell cycles (Jiang et al., 2005; Jiang et al., 2008). A study in West African children reported a strong inverse correlation between the exposure of aflatoxin and body height increase (Gong et al., 2004). Fumonisins, a group of mycotoxins produced by fungal species belonging to the Fusarium genus, have also been shown to have detrimental health effects. Fumonisins are widely distributed around the world and have been classified as possible carcinogens (Joint FAO/WHO Expert Committee on Food Additives, 2011). A study carried out in South Africa was able to demonstrate a positive correlation between fumonisin exposure and high incidences of human oesophageal cancer (Marasas, 2001). Fumonisin exposure has also been linked with increased occurrences of neural tube defects (Missmer et al., 2006). DON, another mycotoxin produced by fungal species within the Fusarium genus, has not yet been associated with any long-term health impacts in humans but animals with low dose chronic exposure to DON have shown that decreased growth and feed intake (Forsell, Witt, Tai, Jensen, \& Pestka, 1986; Rotter, Thompson, Lessard, Trenholm, \& Tryphonas, 1994). OTA, produced by Aspergillus ochraceus, is a common mycotoxin and a possible human carcinogen. Studies in animals have shown that it has the potential to be carcinogenic, immunosuppressive and neurotoxic (Álavarez, Gil, Ezpeleta, García-Jalón, \& López de Cerain, 2004; Lioi, Santoro, Barbieri, Salzano, \& Ursini, 2004; Schaaf et al., 2002). ZEN is produced by several fungi in the Fusarium genus including: F. culmorum, F. graminearum and F. crookwellense. It has estrogenic effects in pigs (Jiang et al., 2011) and suggested that it can trigger central precocious pubertal in human females (Massart, Meucci, Saggese, \& Soldani, 2007).

Due to the toxic effect of mycotoxins in humans and animals it is important to develop analytical methods to detect them in food in order to facilitate their control and regulation. Liquid chromatography tandem mass spectrometry (LC-MS/MS) is an effective method of detection for mycotoxin analysis. In recent 
years, studies have demonstrated LC-MS/MS methods capable of sub ppb detection for multiple mycotoxins in maize (Frenich, Vidal, Romero-Gonzalez, \& Aguilera-Luiz, 2009; Liao et al., 2013; Malachová, Sulyok, Beltrán, Berthiller, \& Krska, 2014; Zachariasova et al., 2014). Analytical methods for multiple mycotoxins should be selective for their target analytes, sensitive enough to detect toxins at relatively low concentrations and efficient to ensure rapid and reliable analysis.

Recently a mycotoxin study carried out in Tanzania examined the extent of dietary exposure of AFB 1 , $\mathrm{FB}_{1}$ and $\mathrm{DON}$ through the quantification of their respective biomarkers in serum and urine (Shirima et al., 2013; Srey, Kimanya, Routledge, Shirima, \& Gong, 2014). The study found that young children in Tanzania are chronically exposed to $\mathrm{AFB}_{1}, \mathrm{FB}_{1}$ and $\mathrm{DON}$ through their diet. Urinary $\mathrm{FB}_{1}$ was found to be negatively associated with length for age Z-scores whilst the negative association between AF-Alb and child growth did not reach statistical significance. In a recent study in Tanzania, maize kernels were sampled from three districts and multi-mycotoxins were measured by LC-MS method (Kamala et al., 2015). The study reported high occurrence of $\mathrm{AFB}_{1}(50 \%)$ and $\mathrm{FB}_{1}(73 \%)$. The food cooking process is known to have varying impact on mycotoxin levels, therefore measuring the levels of mycotoxins in cooked food can provide more close estimates of exposure than in maize flour.

This paper utilises a recently developed multi-mycotoxin detection method to determine the extent of multi-mycotoxin contamination in the maize porridge, in order to build upon mycotoxin occurrence and exposure data from previous studies; and to compare with the exposure biomarker data where possible.

\section{Materials and Methods}

\subsection{Reagents and chemicals}

Acetonitrile (LC-MS grade), ammonium hydroxide ( $\geq 25 \%$ in water), dimethyl sulfoxide ( $\geq 99.9 \%$ ), formic acid ( $\geq 98 \%$ ), magnesium sulfate (anhydrous, $\geq 99.5 \%$ ), methanol (LC-MS grade), mycotoxin standards (AFB $1, A F B_{2}, A F G_{1}, A F G_{2}, F_{1}, F_{2}, D O N, Z E N$ and $\left.O T A\right)$, sodium chloride ( $\left.\geq 99.0 \%\right)$ and Whatman® Puradisc 4 syringe filters ( $0.2 \mu \mathrm{m}$, PTFE) were all acquired from Sigma-Aldrich (Poole, United Kingdom). Each mycotoxin standard was separately dissolved in acetonitrile $(0.2 \mathrm{mg} / \mathrm{ml}$ solution $)$ and stored at $20^{\circ} \mathrm{C}$. Bondesil $\mathrm{C}_{18}$ was acquired from Agilent Technologies (Waldbronn, Germany).

\subsection{Study design and sampling}


113 Cooked maize porridge samples were collected from households across three rural villages in

114 Tanzania: Nyabula (Iringa region), Kikelelwa (Kilimanjaro region) and Kigwa (Tabora region), which are

115 from different agro-ecological zones. The samples were collected at three time points over the period 116 of a year: Time point 1 (June/July 2010, a maize harvesting season), time point 2 (January 2011, six

117 months after maize was harvested) and time point 3 (June/July 2011, another maize harvesting season

11812 months after time point 1). The cooked porridge samples were dried after collection. A total of 101

119 samples; 10 samples from each village at time points 1 and 2, 14 samples from Nyabula and Kikelelwa 120 villages at time point 3 and 13 samples from Kigwa village at time point 3 were randomly selected. The 121 samples were oven dried and kept frozen at $-80^{\circ} \mathrm{C}$ until extraction for UPLC-MS/MS analysis. A blank maize flour sample was cooked into a porridge using the same recipe as the other Tanzanian porridge samples, oven dried and subsequently stored at $-80^{\circ} \mathrm{C}$ until LC-MS/MS extraction for UPLC-MS/MS analysis.

\subsection{Extraction procedure and UPLC-MS/MS analysis}

A previously developed multi-mycotoxin UPLC-MS/MS method was adopted for the study. (Oplatowska-Stachowiak et al., 2015). Nine mycotoxins of interest were quantified: $A F B_{1}, A F B_{2}, A F G_{1}$, $\mathrm{AFG}_{2}, \mathrm{FB}_{1}, \mathrm{FB}_{2}, \mathrm{DON}, \mathrm{ZEN}$ and OTA. Briefly, the LC-MS/MS method was developed on a Waters Acquity UPLC coupled to a Xevo TQ-S triple quadrupole mass spectrometer. Sample extraction method was based on QuEChERS method (Lacina et al., 2012). The quantification was achieved by interpolation from a standard curve prepared by spiking the blank matrix samples at 7 different levels with a mixture of mycotoxins before extraction. Calibrant solutions for matrix-matched calibration curves were prepared in blank matrix before extraction. Limits of detection (LOD) and quantification (LOQ) $(\mathrm{S} / \mathrm{N} \geq 10)$ were previously determined in maize as: $A F B_{1} L O D: 0.05 \mathrm{ng} / \mathrm{g}, \mathrm{LOQ}: 0.125 \mathrm{ng} / \mathrm{g} ; \mathrm{AFB}_{2} / \mathrm{AFG}_{1}$ LOD: 0.125 ng/g, LOQ: 0.25 ng/g; AFG 2 LOD: 0.25 ng/g, LOQ: 0.5 ng/g; DON LOD: 5 ng/g, LOQ: 12.5 ng/g; OTA LOD: 0.625 ng/g, LOQ: 1.25 ng/g; ZEN LOD: 2.5 ng/g, LOQ: 5 ng/g. Limits of detection and quantification were determined in wheat as $0.5 \mathrm{ng} / \mathrm{g}$ and $1.0 \mathrm{ng} / \mathrm{g}$ respectively for $\mathrm{FB}_{1}$ and $0.2 \mathrm{ng} / \mathrm{g}$ and $0.5 \mathrm{ng} / \mathrm{g}$ respectively for $\mathrm{FB}_{2}$. 
142 variance between time points within villages where applicable. A $p$ value of $<0.05$ was considered 143 statistically significant for this test and only positive samples >LOD were used. Spearman's rank tests 144 were carried out to test for correlation between the concentration of $\mathrm{AFB}_{1}, \mathrm{FB}_{1}$ and $\mathrm{DON}$. A $p$ value of $<0.05$ was considered statistically significant for this test.

\section{Results}

147 Descriptive statistics for all 101 maize porridge samples are displayed in Table 1a and 1b. Both FB 148 and $\mathrm{FB}_{2}$ were detected in all 101 samples. The mean ratio of $\mathrm{FB}_{1}: \mathrm{FB}_{2}$ for Nyabula, Kikelelwa and Kigwa 149 was $60: 40,60: 40$ and 64:36, respectively, with a mean ratio of $61: 39$ for all samples. Median FB concentration was significantly higher in Kikelelwa $(290.18 \mathrm{ng} / \mathrm{g})$ and Kigwa $(383.54 \mathrm{ng} / \mathrm{g})$ than in 151 Nyabula $60.14 \mathrm{ng} / \mathrm{g})(p=0.000)$. FB 1 concentration was lowest during time point 2 (6 months after harvest) in every village. Eleven percent of the 101 samples analysed showed fumonisin contamination

153 levels greater than the maximum tolerable limit for total fumonisin in maize based foods intended for 154 adult human consumption $\left(\mathrm{FB}_{1}+\mathrm{FB}_{2} \geq 1000 \mathrm{ng} / \mathrm{g}\right.$ ) set by the European Commission (EC) (European 155 Commission, 2006). Fifty-seven percent of samples also exceeded the EC limit for fumonisins in food 156 products intended for infant consumption $\left(\mathrm{FB}_{1}+\mathrm{FB}_{2} \geq 200 \mathrm{ng} / \mathrm{g}\right)$. At least one type of aflatoxin was 157 detected in $50 \%$ of all samples. The mean ratios of $A F B_{1}: A_{F B}$ and $A F G_{1}: A F G_{2}$ for all samples were both 90:10. The data from Kigwa village was chosen for statistical analysis due to the high (94\%) occurrence of aflatoxins in comparison to Kikelelwa (27\%) and Nyabula (24\%). 
161 Levels of mycotoxin contamination in different villages/regions and time points in Tanzania

\begin{tabular}{|c|c|c|c|c|c|c|}
\hline Mycotoxin & $\begin{array}{l}\text { Village/ } \\
\text { Region }\end{array}$ & Time point & $\begin{array}{c}\text { Positive } \\
\text { Samples (\%) }\end{array}$ & Mean (ng/g) & $\begin{array}{c}\text { Median } \\
\text { (ng/g) }\end{array}$ & Range (ng/g) \\
\hline \multirow{12}{*}{ Fumonisin $B_{1}$} & & 1 & $10(100)$ & 158.06 & 109.64 & $41.70-375.64$ \\
\hline & Nyabula/ & 2 & $10(100)$ & 44.96 & 46.54 & $13.01-65.53$ \\
\hline & Iringa & 3 & $14(100)$ & 87.18 & 60.14 & $12.87-421.36$ \\
\hline & & All & $34(100)$ & 95.61 & 60.14 & $12.87-421.36$ \\
\hline & & 1 & $10(100)$ & 555.74 & 393.41 & $218.19-1308.43$ \\
\hline & Kikelelwa/ & 2 & $10(100)$ & 159.38 & 82.10 & $12.65-564.10$ \\
\hline & Kilimanjaro & 3 & $14(100)$ & 438.14 & 311.63 & $36.02-1850.01$ \\
\hline & & All & $34(100)$ & 390.74 & 290.18 & $12.65-1850.01$ \\
\hline & & 1 & $10(100)$ & 533.98 & 489.07 & $36.26-1206.09$ \\
\hline & Kigwa/ & 2 & $10(100)$ & 299.26 & 309.83 & $71.46-554.57$ \\
\hline & Tabora & 3 & $13(100)$ & 394.84 & 328.50 & $57.08-1141.40$ \\
\hline & & All & $33(100)$ & 408.04 & 383.54 & $36.26-1206.09$ \\
\hline \multirow{12}{*}{ Fumonisin $B_{2}$} & & 1 & $10(100)$ & 110.42 & 80.56 & $27.67-261.89$ \\
\hline & Nyabula/ & 2 & $10(100)$ & 28.21 & 28.37 & $9.50-38.06$ \\
\hline & Iringa & 3 & $14(100)$ & 59.35 & 41.84 & $7.25-282.23$ \\
\hline & & All & $34(100)$ & 65.21 & 37.41 & $7.25-282.23$ \\
\hline & & 1 & $10(100)$ & 354.47 & 273.02 & $152.88-867.24$ \\
\hline & Kikelelwa/ & 2 & $10(100)$ & 108.95 & 52.79 & $10.25-414.68$ \\
\hline & Kilimanjaro & 3 & $14(100)$ & 290.03 & 191.24 & $26.18-1286.93$ \\
\hline & & All & $34(100)$ & 255.72 & 191.24 & $10.25-1286.93$ \\
\hline & & 1 & $10(100)$ & 298.68 & 255.38 & $23.57-790.05$ \\
\hline & Kigwa/ & 2 & $10(100)$ & 177.14 & 183.44 & 33.98 - 313.68 \\
\hline & Tabora & 3 & $13(100)$ & 240.68 & 203.59 & $29.71-699.85$ \\
\hline & & All & $33(100)$ & 239.00 & 213.09 & $23.57-790.05$ \\
\hline \multirow{12}{*}{ Aflatoxin $B_{1}$} & & 1 & $4(40)$ & 7.16 & 0.45 & $0.15-27.60$ \\
\hline & Nyabula/ & 2 & $2(20)$ & 7.43 & 7.43 & $7.15,7.70$ \\
\hline & Iringa & 3 & $4(29)$ & 0.34 & 0.33 & $0.20-0.50$ \\
\hline & & All & $8(24)$ & 4.49 & 0.43 & $0.15-27.60$ \\
\hline & & 1 & $1(10)$ & 34.50 & 34.50 & 34.50 \\
\hline & Kikelelwa/ & 2 & $0(0)$ & - & - & - \\
\hline & Kilimanjaro & 3 & $8(57)$ & 2.19 & 0.48 & $0.20-13.05$ \\
\hline & & All & $9(27)$ & 5.78 & 0.65 & $0.20-34.50$ \\
\hline & & 1 & $10(100)$ & 4.05 & 1.15 & $0.40-13.55$ \\
\hline & Kigwa/ & 2 & $10(100)$ & 10.21 & 5.95 & $0.55-25.80$ \\
\hline & Tabora & 3 & $11(85)$ & 0.67 & 0.68 & $0.20-1.55$ \\
\hline & & All & $31(94)$ & 4.73 & 0.95 & $0.20-25.80$ \\
\hline
\end{tabular}


164 Levels of mycotoxin contamination in different villages and time points in Tanzania

\begin{tabular}{|c|c|c|c|c|c|c|}
\hline Mycotoxin & $\begin{array}{l}\text { Village/ } \\
\text { Region }\end{array}$ & Time point & $\begin{array}{c}\text { Positive } \\
\text { Samples } \\
(\%)\end{array}$ & $\begin{array}{l}\text { Mean } \\
(\mathrm{ng} / \mathrm{g})\end{array}$ & $\begin{array}{c}\text { Median } \\
\text { (ng/g) }\end{array}$ & Range (ng/g) \\
\hline \multirow{12}{*}{$\begin{array}{l}\text { Total Aflatoxins } \\
\left(B_{1}+B_{2}+G_{1}+G_{2}\right)\end{array}$} & & 1 & $4(40)$ & 8.26 & 0.80 & $0.15-31.30$ \\
\hline & Nyabula/ & 2 & $2(20)$ & 14.48 & 14.48 & $14.05,14.90$ \\
\hline & Iringa & 3 & $4(29)$ & 0.69 & 0.60 & $0.20-1.35$ \\
\hline & & All & $8(24)$ & 6.48 & 0.93 & $0.15-31.3$ \\
\hline & & 1 & $1(10)$ & 39.70 & 39.70 & 39.70 \\
\hline & Kikelelwa/ & 2 & $0(0)$ & - & - & - \\
\hline & Kilimanjaro & 3 & $8(57)$ & 3.23 & 1.10 & $0.25-14.9$ \\
\hline & & All & $9(27)$ & 7.39 & 1.10 & $0.25-39.7$ \\
\hline & & 1 & $10(100)$ & 6.27 & 1.65 & $0.40-22.7$ \\
\hline & Kigwa/ & 2 & $10(100)$ & 14.91 & 9.58 & $0.55-43.65$ \\
\hline & Tabora & 3 & $11(85)$ & 1.03 & 1.10 & $0.20-2.40$ \\
\hline & & All & $31(94)$ & 7.03 & 1.60 & $0.20-43.65$ \\
\hline \multirow{12}{*}{ Deoxynivalenol } & & 1 & $1(10)$ & 4.65 & 4.65 & 4.65 \\
\hline & Nyabula/ & 2 & $4(40)$ & 127.43 & 101.15 & $14.45-29.30$ \\
\hline & Iringa & 3 & $10(71)$ & 177.72 & 149.85 & $13.35-421.60$ \\
\hline & & All & $15(44)$ & 136.25 & 97.70 & $4.65-421.60$ \\
\hline & & 1 & $10(100)$ & 102.46 & 95.35 & $28.70-245.65$ \\
\hline & Kikelelwa/ & 2 & $9(90)$ & 115.14 & 88.85 & $29.70-306.80$ \\
\hline & Kilimanjaro & 3 & $10(71)$ & 116.31 & 43.80 & $14.60-410.90$ \\
\hline & & All & $29(85)$ & 111.17 & 88.85 & $14.6-410.90$ \\
\hline & & 1 & $0(0)$ & - & - & - \\
\hline & Kigwa/ & 2 & $0(0)$ & - & - & - \\
\hline & Tabora & 3 & $0(0)$ & - & - & - \\
\hline & & All & $0(0)$ & - & - & - \\
\hline \multirow{12}{*}{ Zearalenone } & & 1 & $0(0)$ & - & - & - \\
\hline & Nyabula/ & 2 & $2(20)$ & 12.75 & 12.75 & $12.60,12.90$ \\
\hline & Iringa & 3 & $1(7)$ & 10.20 & 10.20 & 10.20 \\
\hline & & All & $3(9)$ & 11.90 & 12.60 & $10.20-12.90$ \\
\hline & & 1 & $10(100)$ & 86.40 & 59.90 & $21.70-269.90$ \\
\hline & Kikelelwa/ & 2 & $10(100)$ & 47.37 & 52.88 & $11.25-72.10$ \\
\hline & Kilimanjaro & 3 & $7(50)$ & 48.60 & 38.30 & $12.20-109.25$ \\
\hline & & All & $27(79)$ & 62.14 & 46.80 & $11.25-269.90$ \\
\hline & & 1 & $0(0)$ & - & - & - \\
\hline & Kigwa/ & 2 & $0(0)$ & - & - & - \\
\hline & Tabora & 3 & $1(7)$ & 18.10 & 18.10 & 18.10 \\
\hline & & All & $1(3)$ & 18.10 & 18.10 & 18.10 \\
\hline
\end{tabular}


Table 2. Co-occurrence of mycotoxins in Tanzanian maize porridge across all villages

\begin{tabular}{cccccc}
\hline $\begin{array}{l}\text { Village/ } \\
\text { Region }\end{array}$ & Time point & $\begin{array}{c}\text { Frequency of mycotoxins co-occurrence in same sample (\%) } \\
\text { 1 or more } \\
\text { mycotoxins }\end{array}$ & $\begin{array}{c}\text { 2 or more } \\
\text { mycotoxins }\end{array}$ & $\begin{array}{c}\text { 3 or more } \\
\text { mycotoxins }\end{array}$ & $\begin{array}{c}\text { 4 or more } \\
\text { mycotoxins }\end{array}$ \\
\hline \multirow{2}{*}{$\begin{array}{c}\text { Nyabula/ } \\
\text { Iringa }\end{array}$} & 1 & 100 & 40 & 10 & 0 \\
& 3 & 100 & 50 & 20 & 20 \\
& All & 100 & 86 & 29 & 0 \\
Kikelelwa/ & 1 & 100 & 62 & 21 & 6 \\
Kilimanjaro & 2 & 100 & 100 & 100 & 30 \\
& 3 & 100 & 100 & 90 & 10 \\
\hline \multirow{2}{*}{ Kigwa/ } & All & 100 & 79 & 57 & 29 \\
Tabora & 2 & 100 & 91 & 79 & 24 \\
& 3 & 100 & 100 & 10 & 0 \\
\hline All regions & All time points & 100 & 92 & 8 & 0 \\
\hline
\end{tabular}

${ }^{{ } M y c o t o x i n s ~ w e r e ~ o r g a n i s e d ~ i n t o ~} 5$ groups for this co-occurrence analysis: 1 . Total aflatoxins: $A F B_{1}+A F B_{2}+A F G_{1}+A F G_{2} ; 2$. Total fumonisins: $\mathrm{FB}_{1}+\mathrm{FB}_{2}$; 3. DON; 4. ZEN; 5. OTA.

The highest concentration of $\mathrm{AFB}_{1}$ in a single sample was found in Kikelelwa village at $34.50 \mathrm{ng} / \mathrm{g}$ but Kigwa and Nyabula village had more samples with aflatoxins detectable, and also had higher concentrations of aflatoxins; both villages had higher concentrations aflatoxins at time point 2 (during storage) than any other. The Tanzania regulatory limits for $\mathrm{AFB}_{1}$ concentration ( $\mathrm{AFB}_{1} \geq 5 \mathrm{ng} / \mathrm{g}$ ) and total aflatoxins concentrations (total aflatoxins $\geq 10 \mathrm{ng} / \mathrm{g}$ ) in maize, were exceeded in $14 \%$ and $12 \%$ of samples, respectively. DON was detected in $44 \%$ of all samples. Nyabula samples showed a successive increase in DON concentration between time points whereas Kikelelwa samples showed little difference. DON was not detected in any samples from Kigwa village. None of the analysed samples showed concentrations exceeded the EC limit for DON in maize-based foods intended for human consumption (DON $\geq 750 \mathrm{ng} / \mathrm{g}$ ); however, $6 \%$ of samples were above the limit for infant food (DON $\geq 200 \mathrm{ng} / \mathrm{g}$ ). ZEN was detected in $31 \%$ of all samples. ZEN concentration was highest in all three time points for Kikelelwa (mean: $62.14 \mathrm{ng} / \mathrm{g}$; occurrence: $79 \%$ ) however there was no significant difference between any of them $(p=0.335)$. Samples from Nyabula and Kigwa had a noticeably lower occurrence of ZEN ( $9 \%$ and 3\% respectively). Only one sample exceeded the EC limit for ZEN in maizebased foods intended for human consumption (ZEN $\geq 200 \mathrm{ng} / \mathrm{g}$ ). However, $23 \%$ of samples exceeded the limit for infant food (ZEN $\geq 20 \mathrm{ng} / \mathrm{g}$ ). OTA was detected in $5 \%$ of all samples (mean: $3.80 \mathrm{ng} / \mathrm{g}$, 
median: $3.30 \mathrm{ng} / \mathrm{g}$ ). Each sample that had detectable OTA exceeded the EC limit in maize products intended for both human adult and infant consumption (OTA $\geq 3.0 \mathrm{ng} / \mathrm{g}$ and $>0.5 \mathrm{ng} / \mathrm{g}$, respectively).

Overall, total aflatoxin concentration and total fumonisins were found to have a positive correlation by Spearman's rank correlation (correlation coefficient: $0.254, p=0.011$ ), while total aflatoxin was found to be negatively correlated to DON (correlation coefficient: $-0.407, p=0.000$ ). Total fumonisin and DON showed no statistically significant correlation $(p=0.919)$. ZEN showed no statistically significant correlation with any of the other mycotoxins $(p>0.05)$. Further data on co-occurrence can be seen in Table 2.

\section{DISCUSSION}

The LC-MS/MS analysis showed that the maize porridge samples collected from the three Tanzanian villages were subject to contamination of multiple mycotoxins. All three Tanzanian villages showed high occurrences of fumonisins (detected in $100 \%$ of samples) for all 101 samples. In all villages a lower fumonisin concentration was seen in samples taken at time point 2, 6 months after harvest, compared to samples taken at time point 1 , during harvest. The reason for this difference is not immediately apparent. It is possible that as household food supplies from subsistence farming begin to dwindle during the dry season, and residents may be buying maize from other less contaminated areas. It has been suggested that certain strains of bacteria can be effective in reducing fumonisin levels in maize and that lactic acid, commonly produced by anaerobic bacteria, has a protective role against the growth of Fusarium species in stored maize (Benedetti, Nazzi, Locci, \& Firrao, 2006). Potentially, the fungal species in the maize has been gradually degraded during storage by a bacterial agent. When all three time points were taken into account, Nyabula had the lowest $\mathrm{FB}_{1}$ mean concentration, followed by Kikelelwa. It is possible that the climate or seasonal weather variation in Nyabula may have had an influence in preventing the Fusarium growth in the maize. In terms of maize total aflatoxin concentration, Kigwa had the most positive samples for total aflatoxins, followed by Kikelelwa and Nyabula. Unlike fumonisins, maize aflatoxin concentration was highest in time point 2 compared to time points 1 and 3 . This difference in concentrations between the two mycotoxins would suggest that the storage conditions are favoured by fungi that produce aflatoxins and field or harvest conditions at harvest are favoured by fungi that produce fumonisins. This also suggests that the overall climate and weather conditions of Tanzania are favourable for both aflatoxins and fumonisins. 
214 It was found that Kikelelwa samples showed the highest frequency of DON in maize followed by

215 Nyabula whilst DON was not detected in any samples from Kigwa. Kikelelwa has a temperature climate 216 which is known to favour growth of DON producing fungi. Unlike aflatoxins and fumonisins, DON 217 concentration between time points was not found to be statistically different. ZEN concentration showed 218 a similar contamination pattern to DON; it was highest in Kikelelwa, followed by Nyabula and Kigwa, where it was only detected in $<1 \%$ of samples. ZEN occurrence was highest in Kikelelwa village and lowest in Kigwa. The difference in ZEN concentration between time points was not found to be significant in any villages. OTA was the least prevalent of nine mycotoxins analysed. The low frequency meant that it was not possible to ascertain any discernable pattern in the contamination either between regions or time points.

There were several cases of multiple mycotoxins co-contamination in the analysed maize porridge samples. Mycotoxins were collated into five groups for co-contamination analysis: 1. Total aflatoxins: $A F B_{1}+A F B_{2}+A F G_{1}+A F G_{2} ; 2$. Total fumonisins: $F_{1}+F_{2} ; 3 . D O N ; 4 . Z E N$ and 5. OTA. It was found that $82 \%$ of all samples contained two or more groups of mycotoxins, $36 \%$ contained three or more and $10 \%$ contained four or more. Samples taken from Kikelelwa contained the greatest proportion of cocontaminated samples with $79 \%$ containing three or more groups of mycotoxins. This is much greater in comparison to Nyabula and Kigwa where $21 \%$ and $6 \%$ of samples were co-contaminated with three or more groups of mycotoxins respectively. Certain mycotoxins also showed patterns of cocontamination in terms of their ratios to one another. The $\mathrm{FB}_{1}: \mathrm{FB}_{2}$ ratio of $60: 40$ stayed largely consistent for samples across all regions and time points. $A F B_{1}: A F B_{2}$ and $A F G_{1}: A F G_{2}$ both showed 90:10 ratios. Total aflatoxins and fumonisins showed statistically significant correlations with each other. Aflatoxins and fumonisins were found to have a positive correlation $(r=0.254, p=0.011)$ despite showing different general contamination patterns between time points. This suggests that, even though aflatoxin and fumonisins contamination may differ between seasons, the climate of Tanzania still promotes the growth of certain Aspergillus and Fusarium fungal species. Aflatoxins and DON were found to have a moderate negative correlation. This is most evident in Kigwa village which showed the highest aflatoxin contamination frequency but the lowest for DON. These two correlations highlight the need to further investigate and understand the nature of mycotoxin co-contamination. 
243

244

245

246

247

248

249

250

251

252

253

254

255

256

257

258

259

260

261

262

263

264

265

266

267

268

269

270

271

272

Many of the samples exceeded EC regulatory limits for maize in both adult and infant food. Tanzania has official regulations for $\mathrm{AFB}_{1}$ and total aflatoxins in maize but not for the other previously mentioned mycotoxins. Regulatory limits taken from European Commission Regulation No. 1881/2006, as amended, were used as a guideline for the other mycotoxins involved this study. Total aflatoxins and fumonisins were found to exceed the limits in $12 \%$ and $11 \%$ of samples, respectively. DON and ZEN were the two mycotoxins with the lowest number of samples over the limit at $0 \%$ and $1 \%$, respectively. OTA was unique in that it was detected in only five samples but each of those exceeded the regulatory limit. The maize porridge was also compared against EC regulatory limits for food intended for infant consumption which are much lower than their adult counterparts. $50 \%, 57 \%, 6 \%$ and $23 \%$ of samples were over the infant limit for total aflatoxins, total fumonisins, DON and ZEN, respectively based on EC limits. These results show that the mycotoxins in these maize porridge samples are not just a health risk to infants and young children but also a serious risk to adults. Combine this with the fact that many of these samples are co-contaminated with multiple toxins and there is a very real possibility that a large number of these children are consuming food over the recommended limits of several different mycotoxins.

One of the applications of multi-mycotoxin food analysis such as this is to utilise the data in ongoing biomarker discovery and validation. The data in this study has been compared to biomarker data for samples taken from these villages at the same time points, to determine whether $F_{1}, A F B_{1}$ and $D O N$ contamination in food are consistent with urinary $\mathrm{FB}_{1}\left(\mathrm{uFB}_{1}\right)$, aflatoxin albumin adduct (AF-Alb) and urinary DON (uDON) (Shirima et al., 2013; Srey et al., 2014). Generally speaking, uDON concentration in each Tanzanian village reflected the DON concentrations measured in maize food. The Kigwa maize samples showed no trace of DON and this was reflected in the UDON biomarker levels being the lowest out of the three villages. Table 1b shows the Kikelelwa median DON concentration was similar between time points 1 and 2 with a much lower level at time point 3 , which is mirrored in the estimated DON intake from the biomarker study. The Nyabula median DON showed a constant rise from time point 1 through to 3 which is the same pattern as reported in the biomarker study (Srey et al. 2014).

The comparison of $\mathrm{AFB}_{1}$ in maize porridge and $\mathrm{AF}-\mathrm{Alb}$ biomarker in blood was not entirely consistent. The increase in the $\mathrm{AFB}_{1}$ median concentration from time point 1 to 2 in Kigwa village was in a good agreement with a similar increase in AF-Alb from the same time points. However the maize and AF- 
273 Alb data for time point 3 do not agree with each other - a decrease was observed in maize AFB

274 whereas AF-Alb stayed the same as time point 2 (Shirima et al., 2013). A possible explanation for this 275 is the increased consumption due to child growth and maize availability at harvest. Also the children may have still been consuming the same $A F B_{1}$ contaminated maize from time point 2 which may still affect the AF-Alb biomarker measurements.

The $\mathrm{FB}_{1}$ found in this study was also compared against that of $\mathrm{FFB}_{1}$ biomarker obtained from the same village and time points. Nyabula village showed the lowest $\mathrm{FB}_{1}$ contamination in maize but it was Kikelelwa which showed the lowest $\mathrm{FB}_{1}$ detected in urine. The lower exposure in Kikelelwa is presumably due to lower $\mathrm{FB}_{1}$ intake of children due to lower maize consumption but high other food types than in the other two villages. It was observed that time point 2 consistently had the lowest $\mathrm{FB}_{1}$ contamination in maize and this is in consistent with uFB1 levels.

This study was compared against myctoxin occurrence data in maize from Cameroon (Abia et al., 2013), Nigeria (Ezekiel et al., 2014), Malawi (Matumba, Sulyok, Monjerezi, Biswick, \& Krska, 2014), two South African studies (Shephard et al., 2013; van der Westhuizen et al., 2010) and another Tanzanian study with uncooked maize samples taken from the same Kikelelwa village at the same season (Kimanya et al., 2014). All data sets showed high frequencies of $\mathrm{FB}_{1}$ in maize for their respective areas. The $\mathrm{FB}_{1}$ median for Kikelelwa village determined from this study $(290.18 \mathrm{ng} / \mathrm{g})$ was similar to the $\mathrm{FB}_{1}$ median from the Tanzanian study carried out in the same village (329 ng/g) (Kimanya et al., 2014). Both Cameroon and Nigerian maize $\mathrm{FB}_{1}$ levels were in a similar range as the levels in Kikelelwa and Kigwa village. The two studies from South Africa and the one from Malawi all showed much greater FB levels compared to Tanzania. This comparison shows that $\mathrm{FB}_{1}$ is heavily prevalent throughout Africa but the levels of contamination not only vary between different countries but also within different areas of the same country. The distribution of $\mathrm{AFB}_{1}$ was mixed with the majority of areas showing detected frequencies of $\leq 50 \%$. The two studies featuring maize analysis from Kikelelwa village both showed good agreement with each other. They both gave similar frequencies ( $29 \%$ and $24 \%$, respectively) and medians (0.65 ng/g and $1.27 \mathrm{ng} / \mathrm{g}$, respectively). In comparison to Kigwa village (mean: $0.68 \mathrm{ng} / \mathrm{g}$ ), Cameroon and Nigeria showed relatively higher means (3.5 ng/g and $2.5 \mathrm{ng} / \mathrm{g}$, respectively). The distribution of DON between countries varied largely amongst countries especially if high DON concentrations in Malawi Highlands (mean: 600 ng/g; max: 2328 ng/g) and compared against the lower 
303

304

305

306

307

308

309

310

311

312

313

314

315

316

317

318

319

320

321

322

323

324

325

326

327

328

329

330

relatively high for Kikelelwa of Tanzania when compared against Cameroon and South Africa. Nyabula and Kigwa of Tanzania showed lower ZEN concentrations comparable to Malawi and Nigeria. The limitation of comparing data between different countries is that mycotoxin contamination levels can vary between seasons and years, so conclusions about relative frequencies of contamination between different regions or countries cannot be drawn without multiple sampling over a period of time.

\section{CONCLUSIONS}

The UPLC-MS/MS method was successfully used to detect and quantify the nine mycotoxins of interest from the Tanzanian maize porridge samples. All three Tanzanian villages had a considerable mycotoxin contamination as $82 \%$ of samples contained two or more groups of mycotoxins. Fumonisins were by far the most prevalent mycotoxins as they were detected in all samples. $\mathrm{FB}_{1}$ and $\mathrm{FB}_{2}$ contamination was found to have a seasonal pattern, being lower following a period of storage. AFB 1 was detected primarily in Kigwa, with higher concentrations following storage. DON showed large regional variance, with complete absence from Kigwa village which matched up well the biomarker data in the same village. The data obtained for $\mathrm{AFB}_{1}, \mathrm{FB}_{1}$ and $\mathrm{DON}$ was comparable with exposure findings based on their corresponding biomarkers. Finally, the co-contamination data showed that both Tanzania adults and children from these villages are at risk from multiple mycotoxins in maize. It is not known to what extent co-contamination with multiple mycotoxins may contribute to health effects. This study highlights the need to understand the extent of mycotoxin co-contamination so that proper contamination control can be implemented in these vulnerable areas.

The authors declare that they have no actual or potential conflicts of interest.

Acknowledgement: We acknowledge the funding support by the Leverhulme-Royal Society Africa Award and the administrative support of Tanzania Food and Drugs Authority for this study. The authors would like to thank the subjects and field workers from all the areas where the study was conducted.

\section{References}

Abia, W. A., Warth, B., Sulyok, M., Krska, R., Tchana, N. A., Njobeh, P. B., ... Moundipa, P. F. (2013). Determination of multi-mycotoxin occurrence in cereals, nuts and their products in cameroon by liquid chromatography tandem mass spectrometry (LC-MS/MS). Food Control, 31(2), 438-453. 
331 Álavarez, L., Gil, A. G., Ezpeleta, O., García-Jalón, J. A., \& López de Cerain, A. (2004). Immunotoxic

Azziz-Baumgartner, E., Lindblade, K., Gieseker, K., Rogers, H. S., Kieszak, S., Njapau, H., . . Aflatoxin, I. G. (2005). Case-control study of an acute aflatoxicosis outbreak, kenya, 2004. Environmental Health Perspectives, 113(12), 1779-1783.

Bakırdere, S., Bora, S., Bakırdere, E. G., Aydın, F., Arslan, Y., Komesli, O. T., . . Yıldırım, E. (2012). Aflatoxin species: Their health effects and determination methods in different foodstuffs. Central European Journal of Chemistry, 10(3), 675-685.

Benedetti, R., Nazzi, F., Locci, R., \& Firrao, G. (2006). Degradation of fumonisin B1 by a bacterial strain isolated from soil. Biodegradation, 17(1), 31-38.

Bennett, J. W., \& Klich, M. (2003). Mycotoxins. Clinical Microbiology Reviews, 16(3), 497-516.

European Commission. (2006). Commission regulation (EC) no 1881/2006 of 19 december 2006 setting maximum levels for certain contaminants in foodstuffs. Official Journal, L364, 5-24.

Ezekiel, C. N., Warth, B., Ogara, I. M., Abia, W. A., Ezekiel, V. C., Atehnkeng, J., ... Bandyopadhyay, R. (2014). Mycotoxin exposure in rural residents in northern nigeria: A pilot study using multiurinary biomarkers. Environmental International, 66, 138-145.

Forsell, J. H., Witt, M. F., Tai, J. H., Jensen, R., \& Pestka, J. J. (1986). Effects of 8-week exposure of the B6C3F1 mouse to dietary deoxynivalenol (vomitoxin) and zearalenone. Food \& Chemical Toxicology, 24(3), 213-219.

Frenich, A. G., Vidal, J. L. M., Romero-Gonzalez, R., \& Aguilera-Luiz, M. M. (2009). Simple and highthroughput method for the multimycotoxin analysis in cereals and related foods by ultra-high performance liquid chromatography/tandem mass spectrometry. Food Chemistry, 117(4), 705712. 
Gong, Y. Y., Hounsa, A., Egal, S., Turner, P. C., Sutcliffe, A. E., Hall, A. J., . . Wild, C. P. (2004). Postweaning exposure to aflatoxin results in impaired child growth: A longitudinal study in benin, west africa. Environmental Health Perspectives, 112(13), 1334-1338.

Huang, L. C., Zheng, N., Zheng, B. Q., Wen, F., Cheng, J. B., Han, R. W., . . Wang, J. Q. (2013). Simultaneous determination of aflatoxin M1, ochratoxin A, zearalenone and $\alpha$-zearalenol in milk by UHPLC-MS/MS. Food Chemistry, 146, 242-249.

International Agency for Research on Cancer. (2002). IARC monographs on the evaluation of carcinogenic risks to humans; some mycotoxins, lyons france

Jiang, S. Z., Yang, Z. B., Yang, W. R., Gao, J., Liu, F. X., Broomhead, J., \& Chi, F. (2011). Effects of purified zearalenone on growth performance, organ size, serum metabolites, and oxidative stress in postweaning gilts. Journal of Animal Science, 89, 3008-3015.

Jiang, Y., Jolly, P. E., Ellis, W. O., Wang, J. S., Phillips, T. D., \& Williams, J. H. (2005). Aflatoxin B1 albumin adduct levels and cellular immune status in ghanaians. International Immunology, 17(6), 807-814.

Jiang, Y., Jolly, P. E., Preko, P., Wang, J. S., Ellis, W. O., Phillips, T. D., \& Williams, J. H. (2008). Aflatoxin-related immune dysfunction in health and in human immunodeficiency virus disease. Clinical \& Developmental Immunology, 2008, 1-12.

Joint FAO/WHO Expert Committee on Food Additives. (2011). Evaluation of certain food additivies and contaminants, seventy-fourth report of the joint FAO/WHO expert committee on food additives

Kamala, A., Ortiz, J., Kimanya, M., Haesaert, G., Donoso, S., Tiisekwa, B., \& De Meulenaer, B. (2015). Multiple mycotoxin co-occurrence in maize grown in three agro-ecological zones of tanzania. Food Control, 54, 208-215. 
Kimanya, M. E., Shirima, C. P., Magoha, H., Shewiyo, D. H., De Meulenaer, B., Kolsteren, P., \& Gong, Y. Y. (2014). Co-exposures of aflatoxins with deoxynivalenol and fumonisins from maize based complementary foods in rombo, northern tanzania. Food Control, 41, 76-81.

Lacina, O., Zachariasova, M., Urbanova, J., Vaclavikova, M., Cajka, T., \& Hajslova, J. (2012). Critical assessment of extraction methods for the simultaneous determination of pesticide residues and mycotoxins in fruits, cereals, spices and oil seeds employing ultra-high performance liquid chromatography-tandem mass spectrometry. Journal of Chromatography A, 1262, 8-18.

Liao, C. D., Wong, J. W., Zhang, K., Hayward, D. G., Lee, N. S., \& Trucksess, M. W. (2013). Multimycotoxin analysis of finished grain and nut products using high-performance liquid Chromatography-Triple-quadrupole mass spectrometry. Journal of Agricultural and Food Chemistry, 61(20), 4771-4782.

Lioi, M. B., Santoro, A., Barbieri, R., Salzano, S., \& Ursini, M. V. (2004). Ochratoxin A and zearalenone: A comparative study on genotoxiceffects and cell death induced in bovine lymphocytes. Mutation Research, 557(1), 19-27.

Malachová, A., Sulyok, M., Beltrán, E., Berthiller, F., \& Krska, R. (2014). Optimization and validation of a quantitative liquid chromatography-tandem mass spectrometric method covering 295 bacterial and fungal metabolites including all regulated mycotoxins in four model food matrices. Journal of Chromatography A, 1362, 145-156.

Marasas, W. F. O. (2001). Discovery and occurrence of the fumonisins: A historical perspective. Environmental Health Perspectives, 109(2), 239-243.

Massart, F., Meucci, V., Saggese, G., \& Soldani, G. (2007). High growth rate of girls with precocious puberty exposed to estrogenic mycotoxins. The Journal of Pediatrics, 152(5), 690-695.

Matumba, L., Sulyok, M., Monjerezi, M., Biswick, T., \& Krska, R. (2014). Fungal metabolites diversity in maize and associated human dietary exposures relate to micro-climatic patterns in malawi. Journal of Agricultural Food and Chemistry, 8(34), 269-282. 
403

404

405

406

407

408

409

410

411

412

413

414

415

416

417

418

419

420

421

422

423

424

425

426

Missmer, S. A., Suarez, L., Felkner, M., Wang, E., Merrill, A. H., Rothman, K. J., \& Hendricks, K. A. (2006). Exposure to fumonisins and the occurrence of neural tube defects along the texasmexico border. Environmental Health Perspectives, 114(2), 237-241.

Nyikal, J., Misore, A., Nzioka, C., Njuguna, C., Muchiri, E., Njau, J., . . Bowen, A. (2004). Outbreak of aflatoxin poisoning - eastern and central provinces, kenya, january-july 2004 78. Morbidity and Mortality Weekly Report, 53(34), 790-793.

Oplatowska-Stachowiak, M., Haughey, S. A., Chevallier, O. P., Galvin-King, P., Campbell, K., Magowan, E., ... Elliott, C.,T. (2015). Determination of the mycotoxin content in distiller's dried grain with solubles using a multianalyte UHPLC-MS/MS method. Journal of Agricultural and Food Chemistry, 63(43), 9441-9451.

Rotter, B. A., Thompson, B. K., Lessard, M., Trenholm, H. L., \& Tryphonas, H. (1994). Influence of low-level exposure to fusarium mycotoxins on selected immunological and hematological parameters in young swine. Fundamental and Applied Toxicology, 23(1), 117-124.

Schaaf, G. J., Nijmeijer, S. M., Maas, R. F. M., Roestenberg, P., de Groene, E. M., \& Fink-Gremmels, J. (2002). The role of oxidative stress in the ochratoxin A-mediated toxicity in proximal tubular cells. Biochimica Et Biophysica Acta (BBA) - Molecular Basis of Disease, 1588, 149-158.

Serra, R., Braga, A., \& Venâncio, A. (2005). Mycotoxin-producing and other fungi isolated from grapes for wine production, with particular emphasis on ochratoxin A. Research in Microbiology, 156(4), 515-521.

Shephard, G. S., Burger, H. M., Gambacorta, L., Gong, Y. Y., Krska, R., Rheeder, J. P., . . van der Westhuizen, L. (2013). Multiple mycotoxin exposure determined by urinary biomarkers in rural subsistence farmers in the former transkei, south africa. Food and Chemical Toxicology, 62, 217225.

Shirima, C. P., Kimanya, M. E., Kinabo, J. L., Routledge, M. N., Srey, C., Wild, C. P., \& Gong, Y. Y. (2013). Dietary exposure to aflatoxin and fumonisin among tanzanian children as determined using biomarkers of exposure. Molecular Nutrition \& Food Research, 57(10), 1874-1881. 
Srey, C., Kimanya, M. E., Routledge, M. N., Shirima, C. P., \& Gong, Y. Y. (2014). Deoxynivalenol exposure assessment in young children in tanzania. Molecular Nutrition \& Food Research, 58(7), 1574-1580.

Van de Perre, E., Deschuyffeleer, N., Jacxsens, L., Vekeman, F., Van Der Hauwaert, W., Asam, S., . . .De Meulenaer, B. (2014). Screening of moulds and mycotoxins in tomatoes, bell peppers, onions, soft red fruits and derived tomato products. Food Control, 37, 165-170.

van der Westhuizen, L., Shephard, G. S., Rheeder, J. P., Burger, H. M., Gelderblom, W. C., Wild, C. P., \& Gong, Y. Y. (2010). Simple intervention method to reduce fumonisin exposure in a subsistence maize-farming community in south africa. Food Additives \& Contaminants: Part A, $27(11), 1582-1588$.

Wild, C. P., \& Gong, Y. Y. (2010). Mycotoxins and human disease: A largely ignored global health issue. Carcinogenesis, 31(1), 71-82.

Williams, J. H., Phillips, T. D., Jolly, P. E., Stiles, J. K., Jolly, C. M., \& Aggarwal, D. (2004). Human aflatoxicosis in developing countries: A review of toxicology, exposure, potential health consequences, and interventions. The American Journal of Clinical Nutrition, 80(5), 1106-1122.

Yogendrarajah, P., Van Poucke, C., De Meulenaer, B., \& De Saeger, S. (2013). Development and validation of a QuEChERS based liquid chromatography tandem mass spectrometry method for the determination of multiple mycotoxins in spices. Journal of Chromatography A, 1297, 1-11.

Zachariasova, M., Dzuman, Z., Veprikova, Z., Hajkova, K., Jiru, M., Vaclavikova, M., . . Hajslova, J. (2014). Occurrence of multiple mycotoxins in european feedingstuffs, assessment of dietary intake by farm animals. Animal Feed Science and Technology, 193, 124-140. 